\title{
Submucosal tunneling and septum myotomy as an endoscopic treatment for symptomatic epiphrenic diverticulum
}

Epiphrenic diverticulum is a rare disorder, with an incidence of $1 / 500000$, and is more usually related to esophageal motility disorders including achalasia [1].

A 76-year-old woman was referred to our service for dysphagia, blockages, and retrosternal pain. She experienced several episodes of aspiration pneumonia. The esophagogram showed a large diverticulum, $10 \mathrm{~cm}$ above the diaphragm, with an important contrast reflux. A manometry was performed and showed no aperistalsis but the esophagogastric junction could not be passed. We performed a computed tomography (CT) scan with oral contrast, which showed a $3.5 \times 5.7 \mathrm{~cm}$ epiphrenic diverticulum ( $\triangleright$ Fig. 1).

Thoracic surgery was contraindicated for this elderly woman and peroral endoscopic myotomy (POEM) [2-4] was proposed to cut the septum. We performed a submucosal tunneling dissection $7 \mathrm{~cm}$ above the diverticulum using a $1.5 \mathrm{~mm}$ Dual Knife (Olympus, Tokyo, Japan). Once we reached the septum, we dissected the submucosa until we reached the periesophageal space in the mediastinum. Then, the tunnel was continued $5 \mathrm{~cm}$ under the diverticulum in the esophageal axis to expose the septum. Myotomy was performed selectively on the circular fibers ( $\triangleright$ Fig. 2, Video $\mathbf{1}$ ). The tunnel entrance was then closed using five hemostatic clips (Boston Scientific, Marlborough, Massachusetts, USA). The procedure was performed without any complications with the patient under general anesthesia. Postoperative contrast swallow showed no difference from

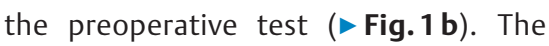
patient resumed feeding at postoperative Day 1 and was discharged at Day 3. At follow-up 2 months later, she was asymptomatic without any aspiration or dysphagia.

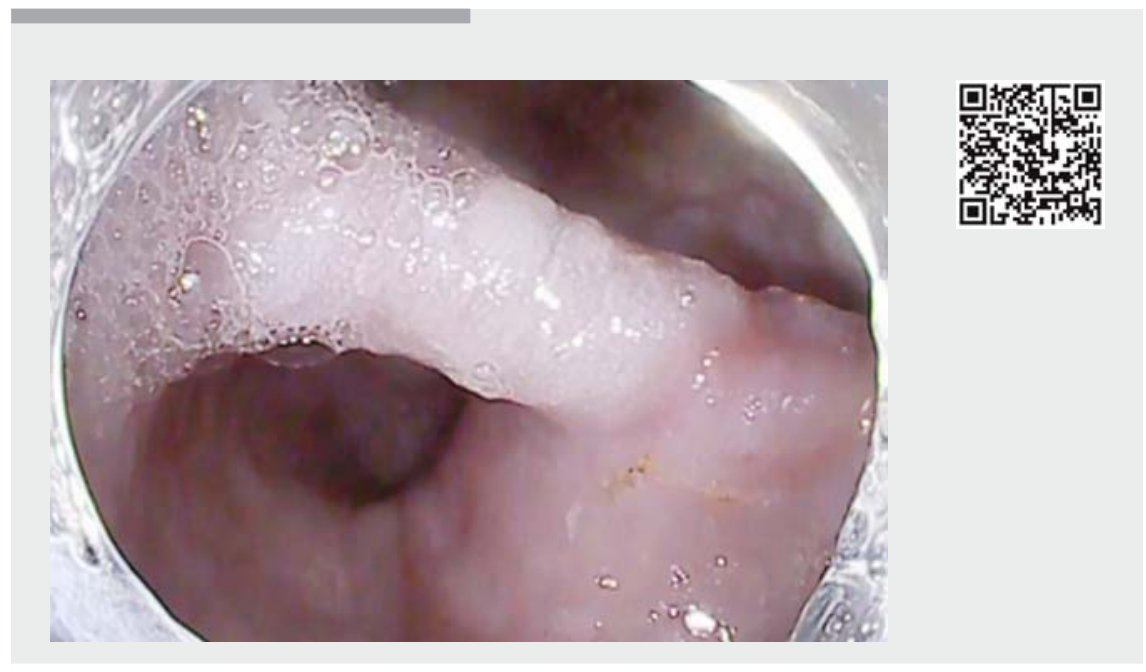

Video 1 Procedure of peroral endoscopic myotomy to cut the diverticulum septum.
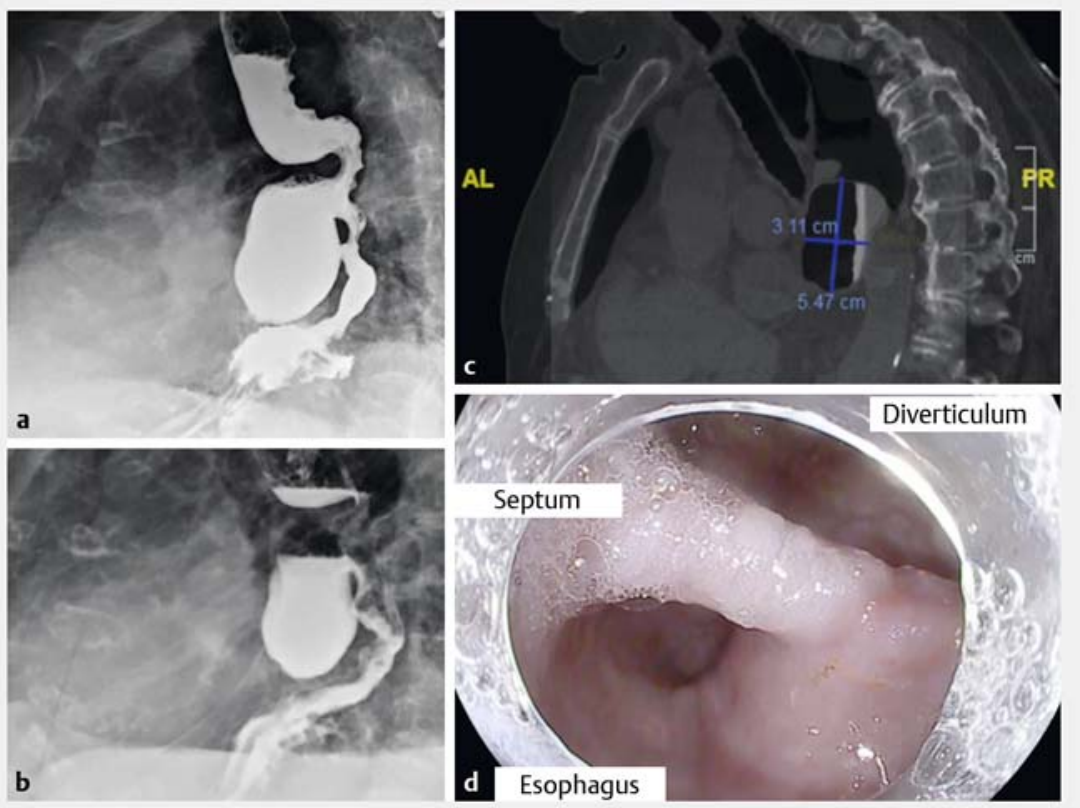

- Fig. 1 The epiphrenic diverticulum. a Contrast swallow showed a large epiphrenic diverticulum in the lower esophagus with no clear stenosis. b Contrast swallow after peroral endoscopic myotomy (POEM). c Computed tomography scan before POEM (AL, anterior left; PR, posterior right). $\mathbf{d}$ Endoscopic aspect of the septum before POEM. 


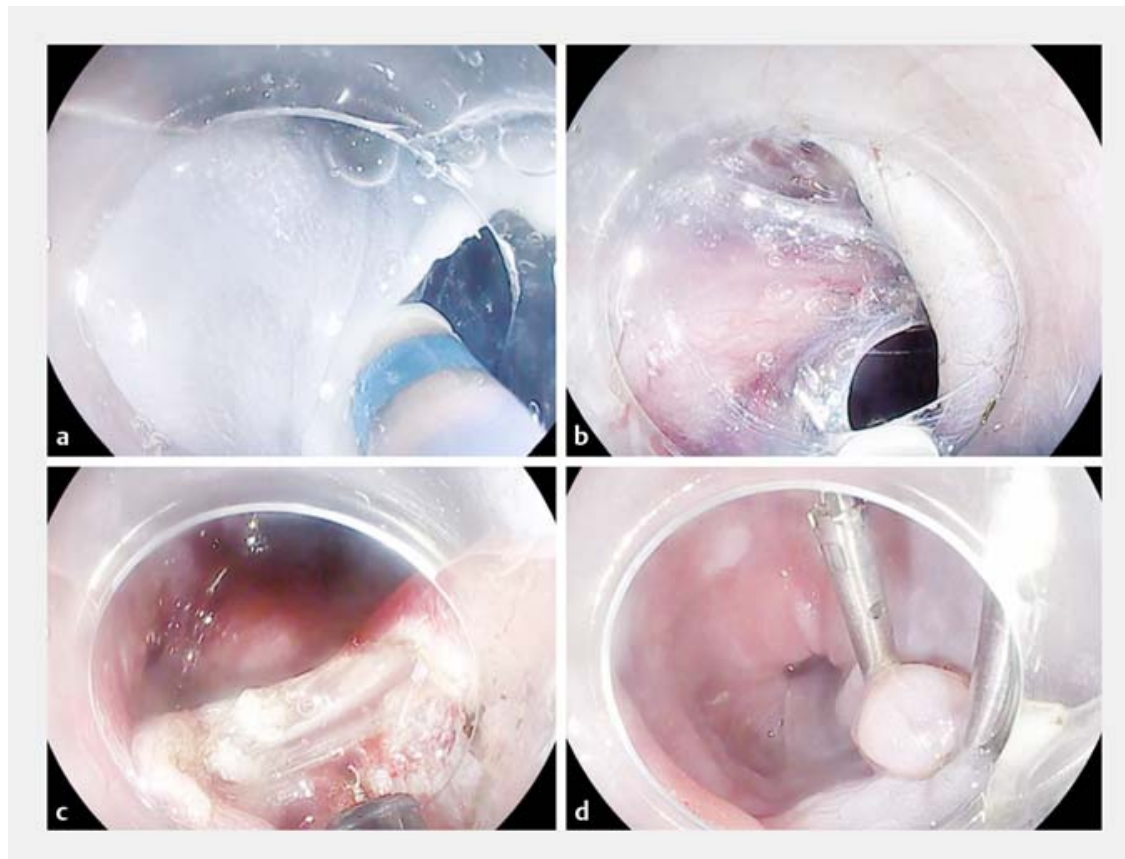

- Fig. 2 Peroral endoscopic myotomy of the septum using submucosal tunneling. a Incision of the mucosa. $\mathbf{b}$ Dissection of the submucosa in the septum, with the mediastinum visible. c Myotomy of the septum. d Closure.
[1] Sonbare D]. Pulsion diverticulum of the oesophagus: more than just an out pouch. Indian J Surg 2015; 77: 44-48

[2] Putignano A, Barthet M, Rio-Tinto R et al. Peroral endoscopic myotomy as a versatile approach to treating complex esophageal disorders. Endoscopy 2018; 50: E172 -E174

[3] Conrado AC, Miranda LEC, Miranda AC et al. Submucosal tunneling endoscopic myotomy of esophageal epiphrenic diverticulum. Endoscopy 2018; 50: E44-E45

[4] Cai M, Xu M, Li Q et al. [Preliminary results of submucosal tunneling endoscopic septum division in the treatment of esophageal diverticulum]. Zhonghua Wei Chang Wai Ke Za Zhi [Chin J Gastrointest Surg] 2017; 20: $530-534$

\section{Bibliography}

DOI https://doi.org/10.1055/a-0733-3579

Published online: 17.10 .2018

Endoscopy 2018; 50: E348-E349

(c) Georg Thieme Verlag KG

Stuttgart · New York

ISSN 0013-726X

\section{ENDOSCOPY E-VIDEOS}

https://eref.thieme.de/e-videos

Lupu $^{1}$, Sabine Roman ${ }^{1,2}$, François Mion',

Thierry Ponchon ${ }^{1}$, Mathieu Pioche ${ }^{1,2}$

1 Department of Endoscopy and Gastroenterology, Pavillon L, Edouard Herriot Hospital, Lyon, France

2 Inserm U1032, Labtau, Lyon, France

\section{Corresponding author}

\section{Mathieu Pioche, MD}

Endoscopy Unit - Digestive Disease Department, Pavillon L - Edouard Herriot Hospital, 69437 Lyon Cedex, France Fax: +33-4-72110147

mathieu.pioche@chu-lyon.fr 